\title{
Evaluation and selection of healthcare waste incinerators using extended sustainability criteria and multi-criteria analysis methods
}

\author{
Adis Puška ${ }^{1}$ (D) . Željko Stević ${ }^{2} \cdot$ Dragan Pamučar $^{3}$
}

Received: 23 February 2021 / Accepted: 11 October 2021 / Published online: 26 October 2021

(c) The Author(s), under exclusive licence to Springer Nature B.V. 2021, corrected publication 2021

\begin{abstract}
Disposal of healthcare waste is a key issue of environmental sustainability in the world. The amount of healthcare waste is increasing every day, and it is necessary to adequately dispose of this kind of waste. There are various treatments for healthcare waste disposal, of which incineration of healthcare waste is one of the solutions. This paper suggests a model for selection of the type of incinerators that best solve the problem of healthcare waste in secondary healthcare institutions in Bosnia and Herzegovina. In the selection of incinerators, extended sustainability criteria were applied. Basic sustainability criteria: environmental, economic, and social criteria, were extended with the technical criterion. To assess which of the incinerators best meets the needs for healthcare waste collection, multi-criteria decision-making was used. For this purpose, a combination of two MCDA methods was applied in this paper, namely full consistency method (FUCOM) and compromise ranking of alternatives from distance to ideal solution (CRADIS). The FUCOM method was applied to determine the weights of the criteria, while the CRADIS method was applied to rank the alternatives. The best alternative of the six alternatives used is A2 (I8-M50), followed by alternative A1 (I8-M40), while the worst ranked alternative is A5 (I8-M100). These results were confirmed by applying the other six methods of multi-criteria analysis and the performed sensitivity analysis. The contribution of this paper is reflected through a new method of multi-criteria analysis that was used to solve decision-making problems. This method has shown simplicity and flexibility in operation and can be used in all problems when it is necessary to make a multi-criteria selection of alternatives.
\end{abstract}

Keywords Medical waste $\cdot$ Compromise ranking of alternatives from distance to ideal solution (CRADIS) · Incinerators · Full consistency method (FUCOM) · Bosnia and Herzegovina

Adis Puška

adispuska@yahoo.com

Extended author information available on the last page of the article 


\section{Introduction}

The amount of healthcare waste (HCW) is growing especially in the last few decades, and, according to Thakur and Ramesh (2015), one of the major reasons for this trend is because of growth of population and demand for health services. Badi, et al. (2019) explained $\mathrm{HCW}$ as a category of waste produced by operations of health and laboratory services. Waste generated in healthcare institutions is classified into three main groups: municipal waste, HCW, and hazardous waste. Ciplak (2015) identified infectious, pathological, and sharp waste as major categories of HWC. HCW governance is becoming a complex and challenging problem in emerging economies (Li et al., 2020). At the same time, HWC represents very big challenges for public authorities (Hinduja \& Pandey, 2019). Even more, Rafiee and et al., (2016) pointed out that HCW raises high levels of concern about public health and the environment. Improper management of HCW can cause significant environmental pollution (Kumar, et al., 2015) and health problems in terms of the spread of diseases caused by viruses and microorganisms and can generate groundwater pollution as a result of continuous disposal of untreated medical waste in municipal landfills ( $\mathrm{Lu}$, et al., 2016).

HCW directly and indirectly affects health and the environment risking more risks (Geetha, et al., 2019). Healthcare institutions do not have a different approach to HCW which is often mixed with municipal waste (Lee, et al., 2016) which further has consequences for human health and the environment. HCW waste must be disposed of properly. There are different ways of treating HCW such as: incineration, autoclaves, chemical disinfection, disposal in the ground, and deep burial (Geetha, et al., 2019). One can find different advantages and disadvantages within these forms of treatments. Process of selection of the best and most effective HCW treatment technology has been the subject of huge research interest (Shi, et al., 2017), especially because of great environmental and financial effects. When choosing treatments for HCW management, it is necessary to provide a reliable and environmentally friendly HCW management system that is, according to Aung, et al. (2019), one of the most important topics on the agenda for health institutions and local communities.

Selection of appropriate HCW waste management processes is based on comprehensive decision making. In this regard, the decision maker needs to make a decision about several issues. One of these is to select a treatment method in waste management and then which device will be used to best meet the set goals. Different treatment methods have their own pros and cons. This research is not about the problem of treatment selection but is focused on the selection of individual devices within the $\mathrm{HCW}$ incineration treatment. For the purpose of this study, medium-sized healthcare institutions in Bosnia and Herzegovina (B\&H) are investigated, which are most common in $\mathrm{B} \& \mathrm{H}$.

One of commonly used $\mathrm{HCW}$ is an incineration by applying high temperatures to incinerate flammable components in waste (Hu, et al., 2015). The advantage of incineration technology in HCW management can be found in reducing the amount of waste and makes the waste unrecognizable (Hossain, et al., 2012). However, HCW incinerators have a role in increasing environmental air pollution (Datta, et al., 2018). It is therefore necessary to ensure that the waste incineration process is harmless to the environment and public health (Hu, et al., 2015); thus, new standards need to be applied when building new HCW incinerators.

In selection of an adequate incinerator, different criteria can be applied to ensure that an incinerator procured will best meet the set decision-making objectives. Sometimes, 
there are conflicting criteria existing in the selection process; thus, the problem of incinerator selection can be done by applying the method of multi-criteria analysis (MCDA). MCDA methods are used when there are multiple alternatives that need to be evaluated with adequate criteria (Rozman, et al., 2016). According to Đalić, et al. (2020), MCDA is a very useful tool for analyzing complex real-world problems. Nowadays, MCDA methods are increasingly used in analyzing various problems and different new methods have been developed (Stević, et al., 2020). In this study, the problem of incinerator selection was performed using the Compromise Ranking of Alternatives from Distance to Ideal Solution (CRADIS) method, while weight determination was performed using the FUCOM (Full Consistency Method) method.

The task of the CRADIS method is to assist in the selection of the HCW incinerator, which best meets the decision criteria. In the selection, different criteria were used; quantitative, those are obtained from the specifications, and qualitative, those are obtained from the expert. These criteria were used in evaluation of the alternatives of different forms of HCW incinerators. The CRADIS method was based on the utility function and the distance of certain alternatives from ideal and anti-ideal solutions. This method enables in determining which of selected incinerators best meets the needs of secondary healthcare institutions in $\mathrm{B} \& \mathrm{H}$. The most important questions that this paper will answer are the following:

(a) Can MCDA methods be used when choosing an HCW incinerator?

(b) Can the methodology for the selection of HCW incinerators be applied in other industries?

(c) Can a CRADIS-based approach be applied in the selection of HCW incinerators?

The CRADIS method enabled the assessment of all important criteria in the management of HCW. The impact of HCW on human health and the environment was our first consideration in the study. Therefore, appropriate selection criteria were included to select the HCW incinerator that best meets the increasingly stringent requirements in terms of preserving human health and environmental protection. The contribution of this study can be found in applying the new HCW incinerator selection methodology to minimize the risks posed by HCW management.

Apart from the introduction, this paper is organized within 8 sections. The second section is focused on the literature review about the application of MCDA methods in HCW management. The third section of papers explains the research methodology. Case study from practice is given in the fourth section of this paper which also introduces the alternatives assessed in this study and explains which criteria for the alternatives were evaluated. In the fifth section, the weight of the criteria, calculated using the FUCOM method, and the alternatives, evaluated using the CRADIS method, are presented, following with the obtained ranking of HCW incinerators. The sixth section provides the test of results from this study. In the seventh section, the findings from the CRADIS method are discussed. Finally, the eighth section offers the most important conclusions based on the findings.

\section{Literature review}

In this section, an application of the MCDA method in waste management is reviewed, following with an application of the FUCOM method in previous studies. Furthermore, the research gaps and contributions of this research are explained. 


\subsection{Application of MCDA methods in waste management}

In waste management, one can find different decision-making problems. To solve these problems, decision makers look at them from several points of views, considering several criteria. Decision-making is complex because these criteria need to be taken into account. Therefore, decision makers use MCDA methods to make a simple decision. Numerous MCDA methods have been applied in new research in waste management. An overview of the application of these methods is presented in Table 1.

HCW management is a complex process. When operating healthcare facilities, they generate different waste. This waste can be classified into nine main categories: infectious waste, pathological waste, sharps, pharmaceutical waste, genotoxic waste, chemical waste, wastes with high content of heavy metals, pressurized containers, and radioactive waste (Budi et al., 2019; Pamučar et al., 2021). The procedures for handling these types of waste are different. According to Shi et al. (2017), it consists of waste collection, transfer routes, plant location, treatment technology selection, and energy recovery. For adequate care for $\mathrm{HCW}$, one of the most important decisions is about treatment methods. The selection of HCW treatment is a complex problem, as there are strong environmental and economic impacts that influence this choice. Therefore, it is necessary to select the most appropriate and efficient HCW management technologies according to different criteria (Hinduja \& Pandey, 2019).

Liu et al. (2013) pointed out that this is an extensive process to assess potential disposal practices. There is no single $\mathrm{HCW}$ management treatment that meets all the complex decision-making criteria ( $\mathrm{Li}$ et al., 2020), so it is necessary to apply different alternatives for HCW management and apply decision-making in the conditions of criteria conflict (Pamučar et al., 2021). MCDM uses several criteria for evaluation of different alternatives, which sometimes can be conflicting (Biswas et al., 2019). In solving MCDM problems used are different MCDA methods (Rozman et al., 2017). The application of MCDM methods is done due to the existence of different criteria that serve decision makers to consider alternatives for HCW management (Liu et al., 2021). Therefore, the application of MCDA methods is of great help when evaluating an alternative to HCW management (Shi et al., 2017).

MDCA methods have been regularly used in solving HCW management problems. Taghipour et al. (2014) analyzed the HCW management facilities to find the best location for HCW management using the AHP (Analytic hierarchy process) method. Chauhan and Singh (2016) performed a sustainable site selection for the construction of a HCW management plant by performing the fuzzy AHP and TOPSIS (Technique for Order of Preference by Similarity to Ideal Solution) method. Carnero (2020) created the Model Integrating Intuitionistic Fuzzy Set using the PAPRIKA method (Potentially All Pairwise RanKings of all possible Alternatives) to identify the risks of segregation in HCW.

Liu et al. (2013) presented a new MCDM technique based on fuzzy set theory and VIKOR (Higher Criterion Optimization and Compromise Solution) methods for evaluating HCW management treatment in Shanghai, China. Voudrias (2016) used the AHP method to evaluate five different treatments for infectious HCW to select the optimal treatment. Dursun et al. (2011) applied multi-level hierarchical structure and fuzzy logic in assessing HCW management. Lu et al. (2016) performed the interval 2-tuple-induced TOPSIS method for selection for HCW management on the Shanghai example.

Liu et al. (2014) used a modified MULTIMOOR method (Multi-Objective Optimization on the basis of Ratio Analysis plus full multiplicative form) based on interval 


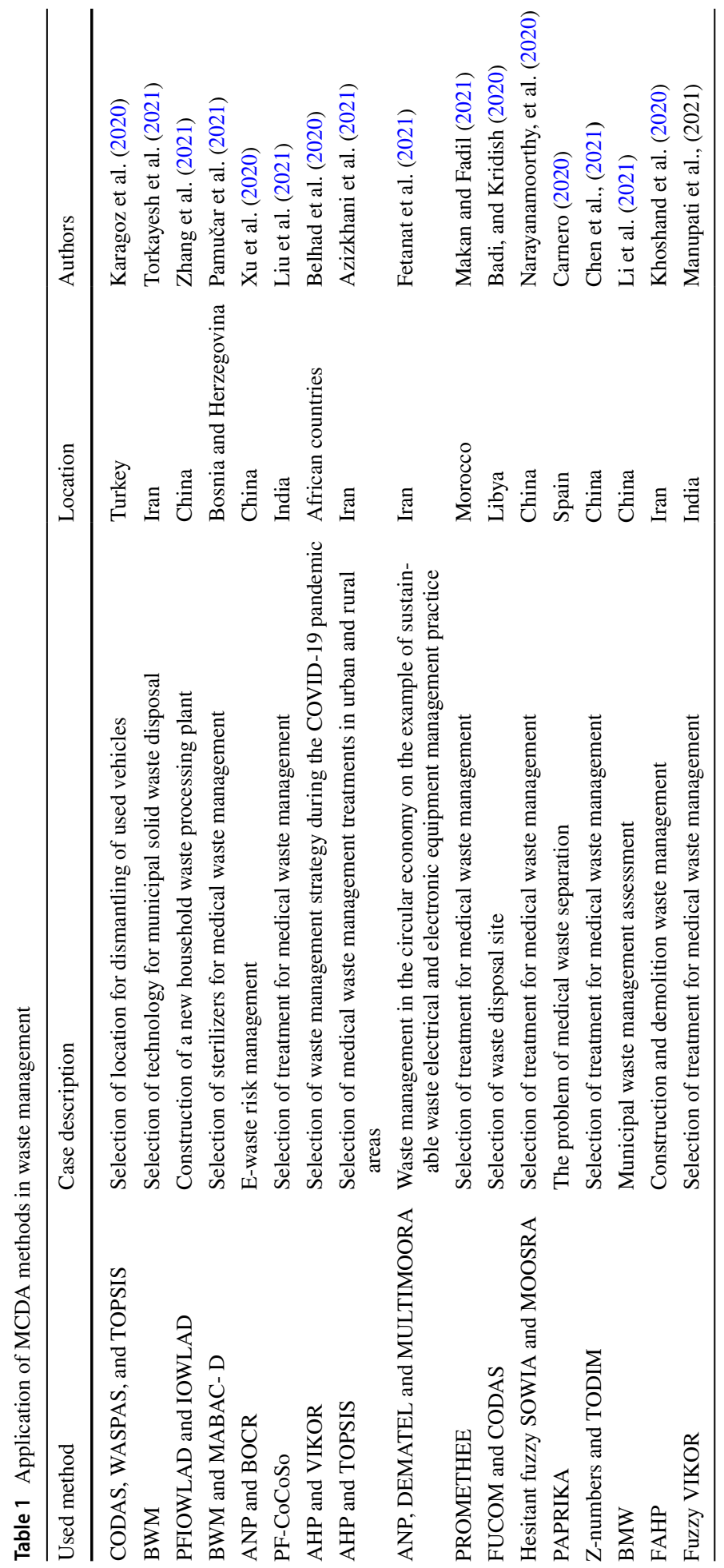


2-tuple linguistic variables in selection of HCW management treatment under uncertain and incomplete information environment on the example of Shanghai, China. Furthermore, Liu et al. (2015), in addition to the MULTIMOOR method, used the DEMATEL method (DEcision MAking Trial and Evaluation Laboratory) on the example of Shanghai, China. Badi et al. (2019) applied Gray numbers to evaluate HCW treatment in Libya.

Xiao (2018) used D numbers to select HCW treatments in Shanghai. Hinduja \& Pandey (2019) applied a complex approach using the methods ANP (Analytical Network Process), AHP and DEMATEL for HCW treatment selection on the example of Chhattisgarh, India. Mishra, et al. (2020) applied the novel EDAS (Evaluation Based on Distance from Average Solution) approach on an intuitionistic fuzzy set for selection of HCW management treatments. Wei and Liao (2016) implemented the Hesitant fuzzy linguistic term set (HFLTS) to select treatments for HCW management on the example of West China Hospital. Adar and Delice (2019) used the MAIRCA (Multi-Attributive Ideal-Real. Comparative Analysis) and MABAC (Multi-Attributive Border Approximation Area Comparison) methods in selection of the most appropriate healthcare waste treatment technology.

From the previous review, it can be concluded that most studies are related to the selection of HCW management treatment. These studies assessed four different HWC treatment methods: incineration, steam sterilization, microwave, and landfill. In some studies, other treatments have been added to these treatments. Voudrias (2016) applied reverse polymerization and chemical disinfection treatments with sodium hypochlorite. Each of these treatments has its pros and cons. Therefore, $\mathrm{Lu}$ et al. (2016) argued that depending on type of HWC, several different treatments can be used. Furthermore, different MCDA methods have been used and therefore the logical choice is to use these methods to solve the HCW management problem.

\subsection{Application of FUCOM and CRADIS method}

The methods to be used in this study are FUCOM and CRADIS. FUCOM is a new method for determining the weight of criteria that was developed in 2018. The FUCOM method was first used to be compared with the AHP and BWM methods showing simplicity and flexibility in operation compared to other methods for determining criteria weights (Pamučar et al., 2018). Therefore, the FUCOM method has been used since then in various studies such as: selection of suppliers, constructors, manufacturer, aircraft selection, landfill site, and logistics centers.

Nunić (2018) conducted the FUCOM method to determine the weights of the criteria while selecting suppliers of PVC profile manufacturers. Cao et al. (2019) used a combination of the SWARA-FUCOM method to determine the weight of the criteria when installing solar panel systems. Stević et al., (2019) used the FUCOM method to determine the weights of criteria in sustainable selection of suppliers on the example of lime manufacturing company. Fazlollahtabar et al. (2019) used the FUCOM method to determine the weights of criteria in evaluation and selection of side-loading forklift. Durmić (2019) applied the FUCOM method to determine the weights of criteria in sustainable selection of suppliers.

Matic and et al. (2019) used a hybrid MCDM model with the FUCOM method to determine the weights of criteria in sustainable selection of suppliers on the example of a construction company. Buddy and Kridish (2020) examined the weights of criteria using the FUCOM method when determining the location for a landfill. Durmic and 
et al. (2020) applied the FUCOM method to determine weights in sustainable supplier selection. Yazdani et al. (2020) applied the FUCOM method to determine the weight of criteria when selecting a logistics center. Hoan and Ha (2021) used the FUCOM method to determine the selection criteria. Blagojevic et al. (2021) used the FUCOM method to determine the weight of criteria for selecting rail crossing modes. Based on these and other studies, it can be concluded that the FUCOM method can be used in determining weights of criteria. This is one of most used methods in newly conducted studies in addition to the AHP method.

The CRADIS method was newly developed and introduced in this study. Since it is a new method, it has not been applied in previous research. This method has not been used so far, and it represents a contribution of this paper. This method seeks to take advantage of the existing methods and as such represents a new concept of using the MCDA methods. The CRADIS method uses existing and modified steps of existing methods, while ranks different alternatives. This approach to creating new methods represents a new approach in the scientific world.

\subsection{Research gaps and contributions}

This research addresses several research gaps. In previous HCW management studies, most attention was paid to the selection of treatment, i.e., the location for construction of the HCW management plant. The studies about the selection of HCW control devices have been rare. One of these studies is conducted by Pamučar et.al. (2021) who selected sterilizers for HCW management purposes. However, the selection of incinerators has not been considered in the literature until now. This study provides a methodological basis about how incinerators can be selected in small and medium medical institutions.

Many MCDA methods, used to rank HCW management alternatives, have been applied in researching HCW management problems. All MCDA methods have their advantages and disadvantages. There have been more and more MCDA methods introduced lately. When developing these methods, an attempt has been made to use different procedures to make this method innovative and different from other methods. However, there is less and less space to develop new methods. The development of the CRADIS method went in such a way that the existing methods and their procedures were used, and a new method has been created. The CRADIC method tries to take the advantages of the methods used while minimizing the disadvantages of these methods. The methodology used is new and opens the possibility of applying several different methods to develop a new method. In this way, new MCDA methods can be developed in future research.

The methodology used in this study provides opportunities to make a simple decision on device selection using extended sustainability criteria. In addition to the classic criteria of sustainability, it is necessary to use the technical characteristics of devices when selecting devices, which are the basis for distinguishing certain devices. Technical characteristics allow similar devices to differ from each other. Based on this, this study provides guidelines on how decisions should be made, while respecting the growing demands regarding environmental protection.

All medical institutions face the problem of waste management. Therefore, smalland medium-sized medical institutions were included in this study to show that all medical institutions must take care of the waste they produce. 


\section{Research methodology}

The selection of the incinerator in this research was done within four phases (Table 2).

The research subject and goal of the research were defined in the first initial phase. After the research goal was established, an expert group was formed. Experts were selected from the company Derby Trade that has been authorized distributor of INCINER8 Limited from London. Three experts from this company were selected to evaluate six different alternatives of the incinerators produced by INCINER8 Limited. Experts were included into the definition of alternatives and criteria for the evaluation of these alternatives. Based on these criteria and alternatives, a questionnaire was created and sent to experts for assessment. The survey questionnaire consisted of two parts. The first part was focused to determine the weights of the criteria, while the second part of the questionnaire was intended to assess the alternatives.

The second phase was about determination of weights of the criteria. With experts' support, the significance of the criteria was first determined, and the criteria were ranked according to that significance. Then, the weight of the criteria was determined in the way that the most significant criterion was given the value 1 , while the other criteria were evaluated with other values reaching the maximum value of 9 . The values of the criteria were given in the form of decimal values. The next step from the FUCOM method was about establishing the weights of the criteria that were determined. The Saaty AHP scale is not

Table 2 Research methodology

Phase 1. Initial phase

Phase 2. Determining the weight of the criteria

Phase 3. Ranking of HCW incinerators

Phase 4 Examination of results and sensitivity analysis

\section{Defining the subject and goal of research \\ Forming an expert group \\ Defining alternatives and criteria \\ Creating a questionnaire \\ Collecting data from experts}

Determining the weights of the main criteria

Ranking and comparison of criteria in a pair of main criteria

Defining the constraints of a nonlinear model

Calculating the values of the main criteria

Determining the weights of sub-criteria

Forming an initial decision matrix

Normalization of the decision matrix

Aggravating the decision matrix

Determining the ideal and anti-ideal solution

Determining deviations from ideal and anti-ideal solutions

Calculating the deviation estimate of alternatives

Calculating the utility function in relation to the deviation from ideal and anti-ideal solutions

Ranking alternatives

Exanimating the obtained results using the CRADIS method with the results obtained using other MCDA methods

Calculating the effects of a dynamic decision matrix

Scenario forming and weight for sub-criteria

Calculating the ranking order alternative for each scenario

Analyzing the obtained results 
used to determine these values. FUCOM does not use a scale of values but only the value for determining criteria. In addition, with the FUCOM method, the most important criterion is assigned a value of 1 , while with the AHP scale, the best value is 9 .

The third phase of the study was focused on ranking HCW incinerators. Based on the experts' ratings of alternatives given in the second part of the questionnaire, the initial decision matrix was formed. In the next step, the collected grades were normalized, following with aggravation of the normalized decision-making matrix. After this step, the ideal and anti-ideal solution was identified and the deviation from these solutions was calculated and assessed. Based on previous steps, the utility function was calculated. The final step was about the ranking of alternatives.

The fourth phase in this study was about sensitivity analysis and examination of the results. This phase was implemented through three steps. Within the first step, the obtained results of the CRADIS method were compared with other MCDA methods. The second step implemented the effects of a dynamic decision matrix. The third step of sensitivity analysis examined the sensitivity of the ranking of alternatives to the change in weight of the sub-criteria. Within the third step, the scenarios were established and the ranking of alternatives for these scenarios was calculated.

In the following section, the used methods for ranking the alternatives are provided.

\subsection{FUCOM method}

The FUCOM method enabled an establishing the weights of criteria in the MCDM environment. This method was developed by Pamučar and et al. (2018) who implemented this method to reduce subjectivity in the decision-making process. The FUCOM method enables the comparison of criteria in pairs, and the validation of results by deviating from the maximum consistency (Nunić 2018). This method, in relation to other methods for determining the subjective weights of criteria, according to Stević and Brković (2020) provides several advantages: reduced number of compared pairs, consistency in comparing criteria, and contributing to rational judgment. The FUCOM method involves creating a nonlinear model based on pairwise comparisons of criteria. The pairwise comparisons of the criteria are made in relation to the most important criterion, which reduces the number of comparisons to $\mathrm{n}-1$. This procedure yields results that are consistent and represent realistic relationships defined by expert preferences. The proposed model eliminates deviations in expert preferences that occur with other subjective methods based on pairwise comparisons, such as the AHP model. We emphasize this because with an increase in the degree of consistency in AHP, expert preferences are distorted, and the values of weight coefficients deviate from the optimal values. This is common in subjective models such as AHP and BWM and is most often due to the use of a nine-level scale that has limited ability to express expert preferences (Asadabadi, et al., 2019). Furthermore, the application of the FUCOM model eliminates the shortcomings of the nine-point scale, which include: (1) low flexibility in expressing expert preferences and (2) causing inconsistencies in paired comparison criteria (Asadabadi, et al., 2019).

According to Pamučar and et al., (2018), the FUCOM method uses the following steps:

Step 1 Criteria/sub-criteria ranking based on expert judgment.

Step 2 Determining the vector of comparative significance for evaluation criteria.

Step 3 Defining the constraints of a nonlinear optimization model. According to Fazlollahtabar, et al. (2019), the values of the weighted coefficients should satisfy two conditions: 
- Condition 1. The ratio of weight coefficients is equal to the comparative significance between the observed, that the condition meets: $w_{k} / w_{k+1}=\varphi_{k /(k+1)}$

- Condition 2. The final values of the weighted coefficients should satisfy the condition of mathematical transitivity, i.e., $\varphi_{k /(k+1)} \times \varphi_{(k+1) /(k+2)=} \varphi_{k /(k+2)}$

Step 4 Defining a model for determining the final values of the weighted coefficients of the evaluation criteria (Božanić et al., 2019).

Step 5 Solving the model and obtaining the final weight of the criteria/sub-criteria $\left(w_{1}, w_{2}, \ldots, w_{n}\right)^{T}$

\subsection{CRADIS method}

The CRADIS method is designed to determine the deviation of alternatives from the ideal and anti-ideal solution. This method is a combination of steps from the methods: ARAS (Additive Ratio ASsessment), MARCOS (Measurement of Alternatives and Ranking according to COmpromise Solut), and TOPSIS methods. The CRADIS method is not a new method, but it is a new approach of using steps from existing methods into a unique combination. This method uses ideal solutions which represent the maximum value of the ideal solution of the alternative, i.e., the minimum value of the alternative by observing the alternatives through all criteria. The steps for implementing the CRADIS method are as follows:

Step 1 Forming an initial decision matrix. The decision matrix in multi-criteria models includes defining a set of " $n$ " criteria and "m" alternatives.

$$
A=\left[\begin{array}{cccc}
x_{11} & x_{12} & \ldots & x_{1 n} \\
x_{21} & x_{22} & \ldots & x_{2 n} \\
\vdots & \vdots & \ddots & \vdots \\
x_{m 1} & x_{m 2} & \ldots & x_{m n}
\end{array}\right]
$$

Step 2 Normalization of decision matrix. Normalization is performed based on the following expressions:

$$
\begin{gathered}
n_{i j}=\frac{x_{i j}}{x_{j \max }} \\
n_{i j}=\frac{x_{j \min }}{x_{i j}}
\end{gathered}
$$

Step 3 Aggravation of decision-making matrices. The aggravated decision matrix is obtained by multiplying the value of the normalized decision matrix by the corresponding weights, based on the following expression:

$$
v_{i j}=n_{i j} \cdot w_{j}
$$

Step 4 Determining the ideal and anti-ideal solution. The calculation of the ideal solution is done by finding the largest value $v_{i j}$ in aggravated decision matrix, while the calculation of the anti-ideal solution is done by finding the smallest value $v_{i j}$ in aggravated decision matrix. 


$$
\begin{aligned}
t_{i} & =\max v_{i j} \\
t_{a i} & =\min v_{i j}
\end{aligned}
$$

Step 5 Calculation of deviations from ideal and anti-ideal solutions.

$$
\begin{aligned}
& d^{+}=t_{i}-v_{i j} \\
& d^{-}=v_{i j}-t_{a i}
\end{aligned}
$$

Step 6 Calculating the grades of the deviation of individual alternatives from ideal and anti-ideal solutions.

$$
\begin{gathered}
s_{i}^{+}=\sum_{j=1}^{n} d^{+} \\
s_{i}^{-}=\sum_{j=1}^{n} d^{-}
\end{gathered}
$$

Step 7 Calculation of the utility function for each alternative in relation to the deviations from the optimal alternatives.

$$
\begin{gathered}
K_{i}^{+}=\frac{s_{0}^{+}}{s_{i}^{+}} \\
K_{i}^{-}=\frac{s_{i}^{-}}{s_{0}^{-}}
\end{gathered}
$$

where $s_{0}^{+}$is the optimal alternative that has the smallest distance from the ideal solution, while $s_{0}^{-}$is the optimal alternative that has the greatest distance from the anti-ideal solution.

Step 8 Ranking alternatives. The final order is obtained by looking for the average deviation of the alternatives from the degree of utility.

$$
Q_{i}=\frac{K_{i}^{+}+K_{i}^{+}}{2}
$$

The best alternative is the one that has the greatest value $Q_{i}$.

\section{Case study}

In practice, there are different types of HCW that can be disposed of in different ways. Burning $\mathrm{HCW}$ is just one method of managing $\mathrm{HCW}$. Compared to other $\mathrm{HCW}$ disposal methods, incineration has several advantages, such as taking up relatively little space, reducing waste, and producing energy (Hu et al., 2015). However, the incineration of HCW also has negative aspects including the impact on health of employees in these incinerators (Ciplak, 2013) and the environmental impact (Ciplak, 2015). Waste minimization and recycling, control of toxic air emissions and alternative incineration procedures are major 
challenges in incinerators (Geetha et al., 2019). The challenges it faces in practice regarding the use of incinerators are numerous, and it is necessary to reduce the risks that arise with the use of HCW incinerators.

When managing HCW in Bosnia and Herzegovina, there are major challenges related to the lack of legal regulations in the field of waste management. Furthermore, there is no precise data on where $\mathrm{HCW}$ is disposed and what the exact volume of $\mathrm{HCW}$ is. It is estimated that $2.2 \mathrm{~kg}$ per capita is produced annually. This amount is currently higher because the amount of HCW is increasing due to measures being taken to prevent the spread of disease caused by the COVID-19 virus (Ramaci et al., 2020). In Bosnia and Herzegovina, there is only one facility that commercially handles HCW, while other HCW care units are located within large hospital centers. When treating HCW in Bosnia and Herzegovina, various treatments are used, most of which are sterilizers and incinerators.

Incinerators are used to destroy the following medical waste: Type I-IV pathological waste, infectious and contaminated "red bag," surgical dressings, plastic test devices, vials \& syringes, yellow bags, bandages and gauzes and other forms of pharmaceutical waste. In $\mathrm{B} \& \mathrm{H}$, several medical waste incinerators have been installed, of which INCINER8 Limited incinerators have been installed at most locations, which is why these incinerators have been taken as an example. These incinerators have been installed in Bihać, Posušje, Brčko, etc. The main problem when installing an incinerator is which type of incinerator to select. It is necessary to choose the type of incinerator that best meets the goals of healthcare institutions.

INCINER8 Limited provides several basic types of incinerators in its portfolio. However, six of them were selected in this paper because certain types of incinerators such as the i8-M15 are used for small clinics, laboratories, and hospitals, while incinerators of the i8-M1000 type are used in large regional hospitals and laboratories. The following incinerators were used as alternatives in this study: I8-M40 (A1), I8-M50 (A2), I8-M70 (A3), I8-M80 (A4), I8-M100 (A5) and I8-M120 (A6). The characteristics and ratings by experts for these incinerators are given in Table 3.

When analyzing and selecting the type of incinerator that best meets the needs of medium-sized healthcare institutions in $\mathrm{B} \& \mathrm{H}$, it is necessary to apply a systematic approach. This approach involves considering the most important criteria for incinerators. To determine the criteria and alternatives in the research, experts were first identified. For that purpose, the company Derby Trade from the City of Brčko was selected, which deals with the procurement and sale of various medical devices. This company is also a distributor of INCINER8 Limited equipment for HCW treatment. They supply HCW treatment equipment to more than ten medical centers.

Questionnaires were distributed to Derby Trade Company and out of the total number of employees; three employees were selected to participate in the survey. These respondents were selected based on their experience in the procurement and distribution of equipment intended for HCW. The first respondent is the director of this company who has 20 years of experience in the procurement and sale of medical instruments. The second respondent is an employee who deals with procurements of medical instruments and has ten years of experience in these assignments. The third respondent is an employee who deals with distribution of medical instruments and has ten years of experience. Respondents were given seven days to complete the questionnaire. After seven days, the questionnaire was collected from this company. All three questionnaires were completed in full, and there was no need to return them for re-completion.

After the experts were selected, they determined all criteria for comparison of different types of selected incinerators. These criteria are presented in Table 4. All criteria were 


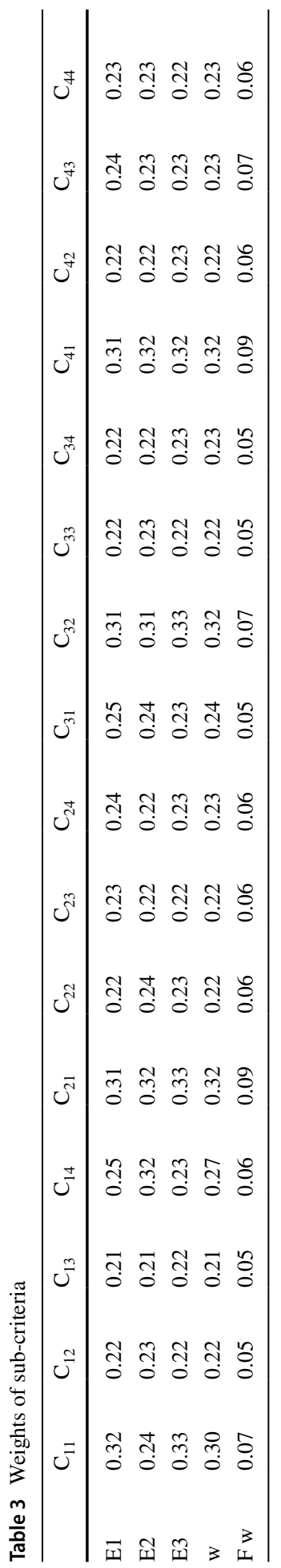




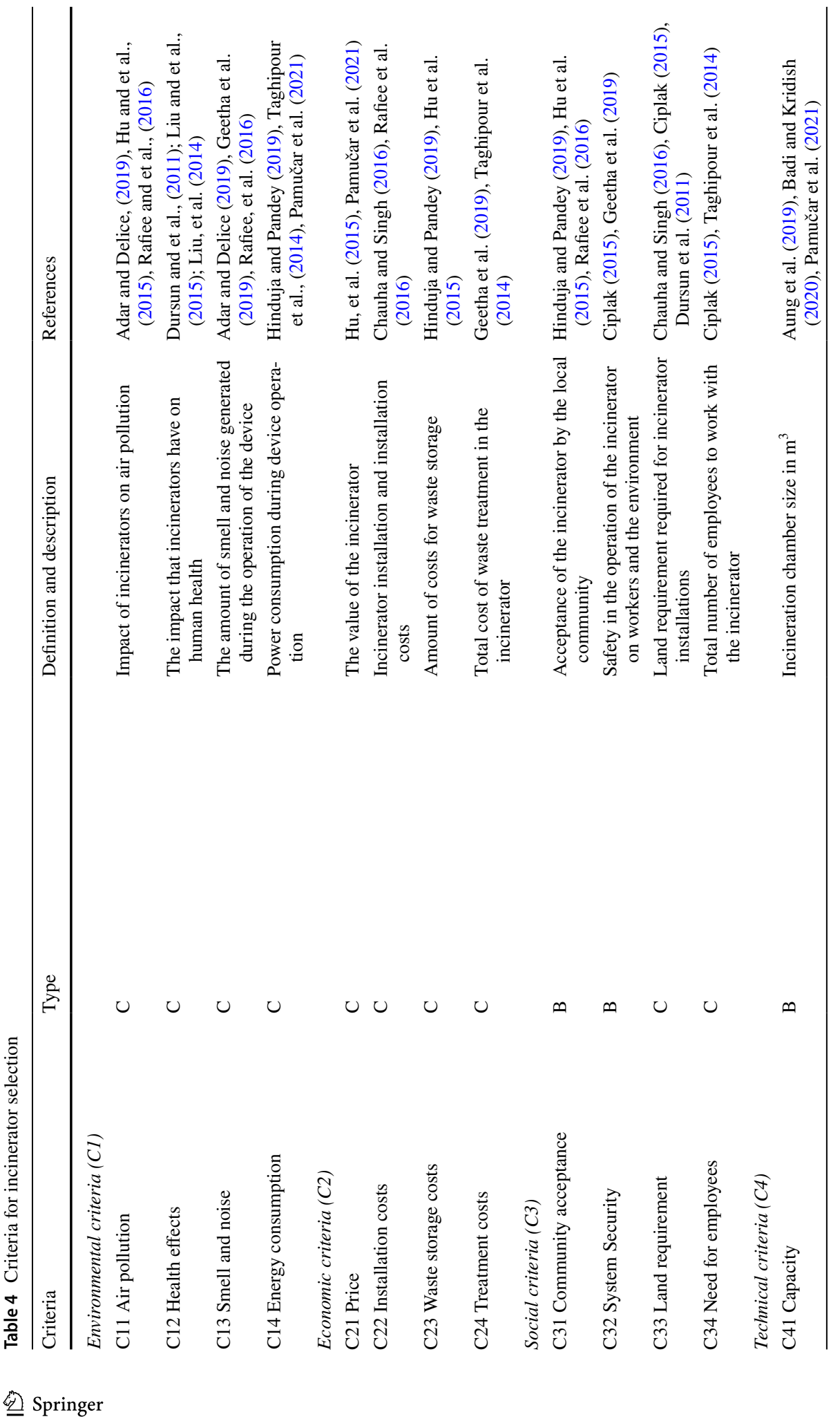




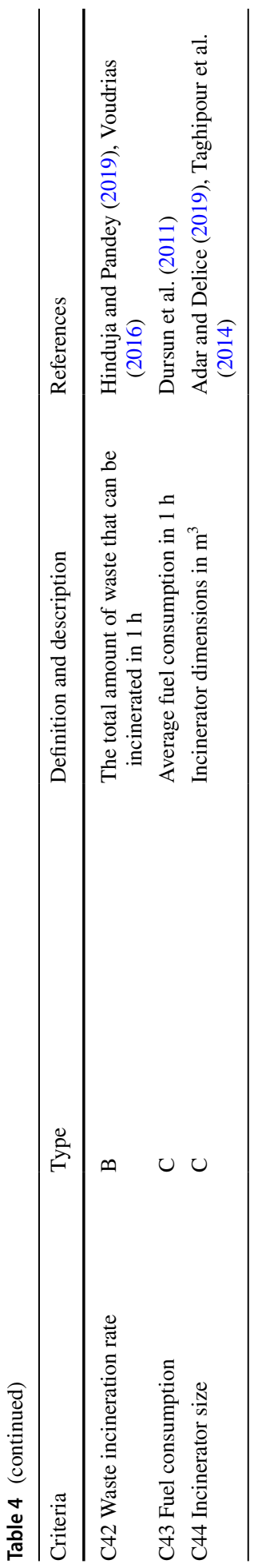


Table 5 Evaluation of the main criteria by experts

\begin{tabular}{lllll}
\hline Expert 1 (E1) & $\mathrm{C} 2$ & $\mathrm{C} 1$ & $\mathrm{C} 4$ & $\mathrm{C} 3$ \\
$\mathrm{C} 2$ (best criterion) & 1 & 2 & 2,3 & 2,9 \\
Expert 2 (E2) & $\mathrm{C} 4$ & $\mathrm{C} 2$ & $\mathrm{C} 1$ & $\mathrm{C} 3$ \\
C4 (best criterion) & 1 & 1,5 & 1,7 & 2,5 \\
Expert 3 (E3) & $\mathrm{C} 4$ & $\mathrm{C} 2$ & $\mathrm{C} 1$ & $\mathrm{C} 3$ \\
$\mathrm{C} 4$ (best criterion) & 1 & 1,3 & 2 & 2,8 \\
\hline
\end{tabular}

divided into four groups: environmental, economic, social, and technical criteria. Based on that grouping, the sustainability criteria were expanded with technical criteria. All these criteria were further broken down into four sub-criteria to avoid some criterion to get greater importance.

The values for the technical criteria were captured from the technical characteristics of the incinerators, while the sustainability criteria were evaluated by selected experts. Depending on the type of sub-criteria, the experts gave grades from one to seven. For benefit (B) sub-criteria, a higher rating meant that this alternative better met the set goals for that criterion, while for cost $(\mathrm{C})$ sub-criteria this rating meant the opposite meaning that if the value of that criterion is lower; it better satisfies the set goals for that sub-criterion. These assessments were given by experts in the first part of the survey questionnaire. After evaluating the alternatives with a particular grade, the experts determined the importance of the criteria and sub-criteria used in this study.

Determining the weights of the criteria and sub-criteria was done using the second part of the survey questionnaire. For this purpose, each expert had to frank the criteria according to the importance they have. The experts determined which, in their opinion, the most important criterion was. The most important criterion was assigned a value of one (1), and other criteria were assigned their values in relation to the most important criteria whose value could be a maximum of nine (9). The less important the criterion, the greater value was assigned.

\section{Results}

Before selection of the incinerator that best meets the needs of secondary healthcare institutions in $\mathrm{B} \& \mathrm{H}$, it was necessary to determine the weights of criteria and sub-criteria by experts. The experts determined the importance of the main criteria (Table 5). The first expert expressed the opinion that the most important criterion for selecting the most suitable incinerator should be economic, followed by ecological, technical, and finally social criteria. The second and third experts believed that the most important criterion for incinerator's selection was the technical, and then the economic and environmental criteria and the least important criterion should be the social criterion. Based on evaluations of the criteria obtained by experts, it can be concluded that they have a different opinion that needs to be harmonized. To harmonize the opinion of the experts, the geometric mean of the weights determined by the individual experts was used (Durmić, 2019). Before harmonization of expert opinions, steps from the FUCOM method were taken to determine the weights of the main criteria.

The harmonized weights showed that the most important criteria according to the experts' assessment is the technical criterion, followed by the economic and social 
criterion, while the social criterion is the least important in their opinion (Table 6). Weights for sub-criteria were determined in the same way for all main criteria (Table 7).

Within the assessment of the environmental criteria by experts, the greatest importance was given by two experts to the sub-criterion Air pollution, while the third expert gave priority to the sub-criterion energy consumption. In assessing the economic criteria, the experts gave the greatest importance to the price sub-criterion, while in the social criteria they gave the greatest importance to the system security sub-criterion. For the technical criteria, the experts gave the greatest importance to the capacity sub-criterion.

From the steps of the FUCOM method, the values of the sub-criteria's weights were obtained (Table 3). Multiplying the weights for the sub-criteria by the weights of the main criteria, the final weights $(\mathrm{F}$ w) were calculated which were used to determine the rank order of the incinerators using the CRADIS method.

The first step in the CRADIS method was to form an initial decision matrix (Table 8). To form the initial decision-making matrix, it was necessary to harmonize different experts' opinions, since three experts participated in this research. The experts evaluated the sustainability sub-criteria with grades from 1 to 7 , while the values for the technical criteria sub-criteria were taken from the technical characteristics of the incinerators (Table 9). The reason why crisp values were taken and not linguistic values is because the CRADIS method has not been used before, so it is necessary to first clarify this method on crisp values. This procedure has been done with other methods that are new and used for the first time (Hwang \& Yoon, 1981; Pamučar \& Ćirović, 2015; Stević et al., 2020; Zavadskas \& Turskis, 2010). To reconcile the opinions of the experts, the average grade was calculated using a geometric mean. Applying this procedure, an initial decision matrix was obtained.

The second step in the application of the CRADIS method was to perform data normalization (Table 10). Since certain sub-criteria have benefit character and some cost character, different expressions were used to calculate the normalization of data. Benefit sub-criteria were calculated using expression 2, while cost criteria were calculated using expression 3 . Using these expressions, a normalized decision matrix was formed.

The third step in applying the CRADIS method was to calculate the aggravated decision matrix (Table 11). To obtain this decision matrix, it was necessary to multiply the normalized data by the appropriate weighting coefficients (expression 4). After an aggravated decision matrix was formed, then the step four was applied within the CRADIS method. This step is about to determine the ideal and anti-ideal solution. The ideal solution represents the maximum value of all elements of the aggravated decision matrix (expression 5), while the anti-ideal solution represents the minimum value of all elements of the aggravated decision matrix (expression 6). The value of the ideal solution is 0.0907 , while the value of the anti-ideal solution is 0.0187 . Once the ideal and anti-ideal solutions were determined, the deviation of the values from the aggravated decision-making matrix of these solutions was calculated. This is step 5 in the CRADIS method.

The specificity of this method is that the distances of individual elements of the aggravated decision matrix from ideal and anti-ideal solutions are calculated (step 6), and then, the values of optimal alternatives (OA) are calculated (Table 12). The optimal alternative is the one that is least distant from the ideal solution and most distant from the anti-ideal solution. After these calculations, step 7 of the CRADIS method was applied to calculate the utility function. The calculation of the utility function was calculated by placing the aggregate values of the deviation from the ideal values in relation to the aggregate optimal alternatives. The final value of the CRADIS method was obtained by looking for the average value of the utility function (step 8). The best alternative is the one that has the highest value of $Q_{i}$. On the example of incinerator selection, the best results are shown 
Table 6 Weights of the main criteria

\begin{tabular}{lllll}
\hline Expert 1 & $\mathrm{C} 1$ & $\mathrm{C} 2$ & $\mathrm{C} 3$ & $\mathrm{C} 4$ \\
& 0.2356 & 0.3298 & 0.2087 & 0.2259 \\
Expert 2 & $\mathrm{C} 1$ & $\mathrm{C} 2$ & $\mathrm{C} 3$ & $\mathrm{C} 4$ \\
& 0.2345 & 0.2417 & 0.2095 & 0.3143 \\
Expert 3 & $\mathrm{C} 1$ & $\mathrm{C} 2$ & $\mathrm{C} 3$ & $\mathrm{C} 4$ \\
& 0.2268 & 0.2520 & 0.2036 & 0.3176 \\
Harmonized & $\mathrm{C} 1$ & $\mathrm{C} 2$ & $\mathrm{C} 3$ & $\mathrm{C} 4$ \\
weights & 0.2337 & 0.2735 & 0.2085 & 0.2843 \\
\hline
\end{tabular}

by alternative A2 (I8-M50), followed by alternative A1 (I8-M40), while the worst results based on expert assessment and technical characteristics of incinerators is shown by alternative A5 (I8-M100). Additional sensitivity analysis was performed to confirm these results.

\section{Examination of results and sensitivity analysis}

Examination of the results and sensitivity analysis was conducted through three steps. The first step was to compare the rankings obtained by the CRADIS method with the rankings obtained by applying other methods. The second step was to calculate the effects of a dynamic decision matrix. The third step was to examine the impact of changing weights of sub-criteria on the ranking of alternatives.

The first step in examining the results was to compare the ranking order obtained by applying other methods. For this purpose, six methods were used: MARCOS, MABAC, SAW (Simple Additive Weighting technique), ARAS, WASPAS (Weighted Aggregated Sum Product ASsessment), and TOPSIS (Technique for Order Performance by Similarity to Ideal Solution). The results obtained by applying these methods showed that the ranking order obtained by the CRADIS method is the same as in the ranking order obtained by the MARCOS, MABAC, SAW, and WASPAS methods. It differs in relation to the ARAS and TOPSIS methods (Table 13). The ARAS method developed by Zavadskas and Turskis (2010) uses a different normalization, and by applying the same normalization as with the CRADIS method, the same ranking order is obtained. In this way, it is shown that the application of different normalizations affects the ranking order of alternatives. Therefore, when comparing methods, it is necessary to apply the same normalization as the influence of normalization on the ranking of alternatives has decreased. The CRADIS method used a different approach when calculating the deviation, so the ranking is therefore more consistent with other methods than with the TOPSIS method.

These results were confirmed by the results obtained using the Spearman correlation coefficient, which showed that the TOPSIS method has the largest deviation from the results of other methods (Table 14). With three alternatives, this ranking order differs, while with the ARAS method it differs with two alternatives. Using other methods, the results obtained by the CRADIS method were confirmed.

The next step in examining the results was the calculation of the effects of the dynamic decision matrix. This approach implies that the worst alternative is discarded, and the value of the remaining alternatives is calculated (Stević et al., 2020). In this study, the analysis 
Table 7 Sub-criteria assessments by experts

\begin{tabular}{lllllllllllllllllll}
\hline & \multicolumn{1}{c}{ Environmental criteria } & \multicolumn{1}{c}{ Economic criteria } & \multicolumn{4}{c}{ Social criteria } & \multicolumn{6}{c}{ Technical criteria } \\
\hline E1 & $\mathrm{C}_{11}$ & $\mathrm{C}_{14}$ & $\mathrm{C}_{12}$ & $\mathrm{C}_{13}$ & $\mathrm{C}_{21}$ & $\mathrm{C}_{24}$ & $\mathrm{C}_{23}$ & $\mathrm{C}_{22}$ & $\mathrm{C}_{32}$ & $\mathrm{C}_{31}$ & $\mathrm{C}_{34}$ & $\mathrm{C}_{33}$ & $\mathrm{C}_{41}$ & $\mathrm{C}_{43}$ & $\mathrm{C}_{44}$ & $\mathrm{C}_{42}$ \\
& 1 & 1.3 & 2.2 & 2.6 & 1 & 1.7 & 2 & 2.1 & 1 & 1.4 & 2 & 2.3 & 1 & 1.5 & 1.8 & 2.2 \\
$\mathrm{E} 2$ & $\mathrm{C}_{14}$ & $\mathrm{C}_{11}$ & $\mathrm{C}_{12}$ & $\mathrm{C}_{13}$ & $\mathrm{C}_{21}$ & $\mathrm{C}_{22}$ & $\mathrm{C}_{24}$ & $\mathrm{C}_{23}$ & $\mathrm{C}_{32}$ & $\mathrm{C}_{31}$ & $\mathrm{C}_{33}$ & $\mathrm{C}_{34}$ & $\mathrm{C}_{41}$ & $\mathrm{C}_{44}$ & $\mathrm{C}_{43}$ & $\mathrm{C}_{42}$ \\
& 1 & 1.5 & 2 & 2.6 & 1 & 1.8 & 2.2 & 2.5 & 1 & 1.6 & 1.8 & 2 & 1 & 2 & 2.1 & 2.4 \\
$\mathrm{E} 3$ & $\mathrm{C}_{11}$ & $\mathrm{C}_{14}$ & $\mathrm{C}_{13}$ & $\mathrm{C}_{12}$ & $\mathrm{C}_{21}$ & $\mathrm{C}_{24}$ & $\mathrm{C}_{22}$ & $\mathrm{C}_{23}$ & $\mathrm{C}_{32}$ & $\mathrm{C}_{34}$ & $\mathrm{C}_{31}$ & $\mathrm{C}_{33}$ & $\mathrm{C}_{41}$ & $\mathrm{C}_{43}$ & $\mathrm{C}_{42}$ & $\mathrm{C}_{44}$ \\
& 1 & 2 & 2.4 & 2.4 & 1 & 2 & 2.2 & 2.5 & 1 & 2 & 2.2 & 2.5 & 1 & 1.8 & 2.2 & 2.3 \\
\hline
\end{tabular}

included four methods: CRADIS, TOPSIS, ARAS, and MARCOS. These methods were taken because the CRADIS method uses the steps from these methods.

When applying the effects of the dynamic decision matrix with the CRADIS method, first alternative A5 was eliminated from the analysis, then alternative A6 and until alternative A2 itself remained. The procedure was applied to other methods in the same way. The obtained results of the effects of the dynamic matrix showed that the rank order of alternatives was not changed with the CRADIS and MARCOS methods, while the rank order was changed with the TOPSIS and ARAS methods (Fig. 1). The TOPSIS method changed the ranking order of alternatives A4 and A6 in scenario 2, while the ARAS method changed the ranking order of A4 and A1 in scenario 3. The results obtained by the CRADIS and MARCOS methods have shown consistency in the ranking of alternatives, while this is not the case with the TOPSIS method and ARAS. Thus, it was confirmed that the algorithm that applies the CRADIS method has shown reliability in ranking alternatives.

The third step was sensitivity analysis. Sensitivity analysis was applied to determine how weight change was used to rank alternatives. In this case, the weight of the sub-criteria was changed to determine how this ranking order is used to rank the alternatives. The first scenario provided the same importance to all sub-criteria $(w=0.0625)$, the other scenarios gave preference to one of the sub-criteria and that sub-criterion, and five times more weight was assigned. Since we used 16 sub-criteria, scenario 17 was formed in this way (Table 15).

By applying these scenarios in the sensitivity analysis for the first 13 scenarios, the same ranking order was obtained (Fig. 2). The reason why there is no difference in these 13 scenarios can be explained with the fact that all incinerators are produced in the same way and according to the same standards and differ only in technical characteristics. Therefore, there are deviations from the ranking order in the last 4 scenarios. In scenario 14, alternative A3 was ranked as the worst alternative, because this alternative, although it has a higher capacity than alternatives A1 and A2, showed worse other values of the sub-criteria and is therefore placed as the last. In scenario 15, there was a change in the ranking of alternatives A1 and A4, also in this scenario alternative A3 was the worst ranked alternative. Alternative A4 can burn waste faster than alternative A2, so this alternative was ranked well than A2. In scenarios 16 and 17, the A1 alternative was the best because it has the lowest fuel consumption and at the same time the lowest surface area, while other incinerators consume more fuel and take up more space.

Sensitivity analysis showed that in most scenarios alternative A2 is the best; only in two scenarios alternative A1 is better. Based on this analysis, it can be concluded that the 


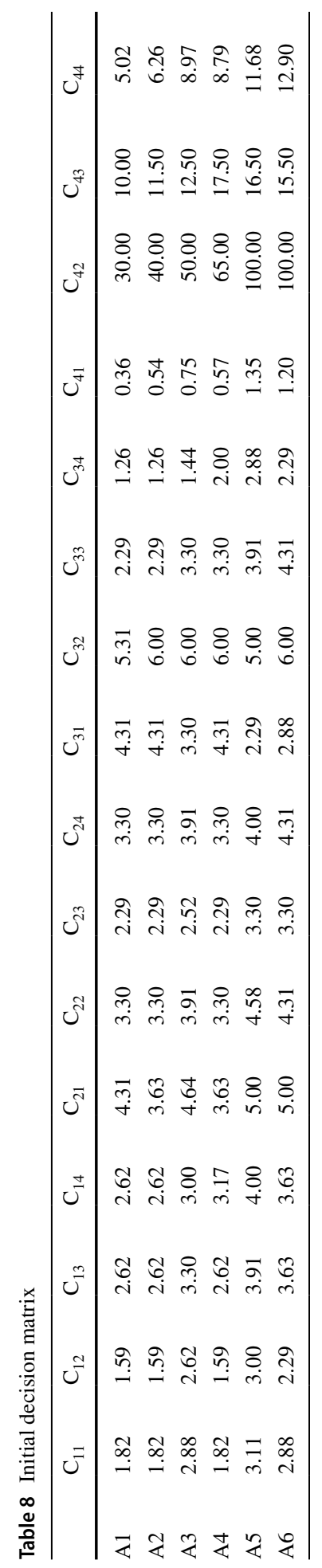


Table 9 Evaluation of alternatives by experts

\begin{tabular}{lllllllllllllllll}
\hline $\mathrm{E} 1$ & $\mathrm{C}_{11}$ & $\mathrm{C}_{12}$ & $\mathrm{C}_{13}$ & $\mathrm{C}_{14}$ & $\mathrm{C}_{21}$ & $\mathrm{C}_{22}$ & $\mathrm{C}_{23}$ & $\mathrm{C}_{24}$ & $\mathrm{C}_{31}$ & $\mathrm{C}_{32}$ & $\mathrm{C}_{33}$ & $\mathrm{C}_{34}$ & $\mathrm{C}_{41}$ & $\mathrm{C}_{42}$ & $\mathrm{C}_{43}$ & $\mathrm{C}_{44}$ \\
\hline $\mathrm{A} 1$ & 3 & 2 & 3 & 3 & 5 & 3 & 3 & 4 & 4 & 5 & 3 & 1 & 0.36 & 30 & 10.0 & 5.02 \\
$\mathrm{~A} 2$ & 3 & 2 & 3 & 3 & 4 & 3 & 3 & 4 & 4 & 6 & 3 & 1 & 0.54 & 40 & 11.5 & 6.26 \\
$\mathrm{~A} 3$ & 4 & 3 & 3 & 3 & 5 & 4 & 4 & 5 & 3 & 6 & 4 & 1 & 0.75 & 50 & 12.5 & 8.97 \\
$\mathrm{~A} 4$ & 3 & 2 & 3 & 4 & 4 & 3 & 3 & 4 & 4 & 6 & 4 & 2 & 0.57 & 65 & 17.5 & 8.79 \\
$\mathrm{~A} 5$ & 5 & 3 & 4 & 4 & 5 & 4 & 4 & 4 & 2 & 5 & 5 & 2 & 1.35 & 100 & 16.5 & 11.68 \\
$\mathrm{~A} 6$ & 4 & 3 & 4 & 4 & 5 & 4 & 4 & 5 & 2 & 6 & 5 & 2 & 1.20 & 100 & 15.5 & 12.90 \\
$\mathrm{E} 2$ & $\mathrm{C}_{11}$ & $\mathrm{C}_{12}$ & $\mathrm{C}_{13}$ & $\mathrm{C}_{14}$ & $\mathrm{C}_{21}$ & $\mathrm{C}_{22}$ & $\mathrm{C}_{23}$ & $\mathrm{C}_{24}$ & $\mathrm{C}_{31}$ & $\mathrm{C}_{32}$ & $\mathrm{C}_{33}$ & $\mathrm{C}_{34}$ & $\mathrm{C}_{41}$ & $\mathrm{C}_{42}$ & $\mathrm{C}_{43}$ & $\mathrm{C}_{44}$ \\
$\mathrm{~A} 1$ & 1 & 2 & 2 & 3 & 4 & 4 & 2 & 3 & 4 & 5 & 2 & 1 & 0.36 & 30 & 10.0 & 5.02 \\
$\mathrm{~A} 2$ & 1 & 2 & 2 & 3 & 4 & 4 & 2 & 3 & 4 & 6 & 2 & 1 & 0.54 & 40 & 11.5 & 6.26 \\
$\mathrm{~A} 3$ & 2 & 3 & 3 & 3 & 5 & 5 & 2 & 3 & 3 & 6 & 3 & 1 & 0.75 & 50 & 12.5 & 8.97 \\
$\mathrm{~A} 4$ & 1 & 2 & 2 & 4 & 4 & 4 & 2 & 3 & 4 & 6 & 3 & 2 & 0.57 & 65 & 17.5 & 8.79 \\
$\mathrm{~A} 5$ & 2 & 3 & 3 & 4 & 5 & 6 & 3 & 4 & 2 & 5 & 3 & 3 & 1.35 & 100 & 16.5 & 11.68 \\
$\mathrm{~A} 6$ & 2 & 2 & 3 & 4 & 5 & 5 & 3 & 4 & 3 & 6 & 4 & 2 & 1.20 & 100 & 15.5 & 12.90 \\
$\mathrm{E} 3$ & $\mathrm{C}_{11}$ & $\mathrm{C}_{12}$ & $\mathrm{C}_{13}$ & $\mathrm{C}_{14}$ & $\mathrm{C}_{21}$ & $\mathrm{C}_{22}$ & $\mathrm{C}_{23}$ & $\mathrm{C}_{24}$ & $\mathrm{C}_{31}$ & $\mathrm{C}_{32}$ & $\mathrm{C}_{33}$ & $\mathrm{C}_{34}$ & $\mathrm{C}_{41}$ & $\mathrm{C}_{42}$ & $\mathrm{C}_{43}$ & $\mathrm{C}_{44}$ \\
$\mathrm{~A} 1$ & 2 & 1 & 3 & 2 & 4 & 3 & 2 & 3 & 5 & 6 & 2 & 2 & 0.36 & 30 & 10.0 & 5.02 \\
$\mathrm{~A} 2$ & 2 & 1 & 3 & 2 & 3 & 3 & 2 & 3 & 5 & 6 & 2 & 2 & 0.54 & 40 & 11.5 & 6.26 \\
$\mathrm{~A} 3$ & 3 & 2 & 4 & 3 & 4 & 3 & 2 & 4 & 4 & 6 & 3 & 3 & 0.75 & 50 & 12.5 & 8.97 \\
$\mathrm{~A} 4$ & 2 & 1 & 3 & 2 & 3 & 3 & 2 & 3 & 5 & 6 & 3 & 2 & 0.57 & 65 & 17.5 & 8.79 \\
$\mathrm{~A} 5$ & 3 & 3 & 5 & 4 & 5 & 4 & 3 & 4 & 3 & 5 & 4 & 4 & 1.35 & 100 & 16.5 & 11.68 \\
$\mathrm{~A} 6$ & 3 & 2 & 4 & 3 & 5 & 4 & 3 & 4 & 4 & 6 & 4 & 3 & 1.20 & 100 & 15.5 & 12.90 \\
\hline
\end{tabular}

Table 10 Normalized decision matrix

\begin{tabular}{lllllllllllllllll}
\hline & $\mathrm{C}_{11}$ & $\mathrm{C}_{12}$ & $\mathrm{C}_{13}$ & $\mathrm{C}_{14}$ & $\mathrm{C}_{21}$ & $\mathrm{C}_{22}$ & $\mathrm{C}_{23}$ & $\mathrm{C}_{24}$ & $\mathrm{C}_{31}$ & $\mathrm{C}_{32}$ & $\mathrm{C}_{33}$ & $\mathrm{C}_{34}$ & $\mathrm{C}_{41}$ & $\mathrm{C}_{42}$ & $\mathrm{C}_{43}$ & $\mathrm{C}_{44}$ \\
\hline $\mathrm{A} 1$ & 1.00 & 1.00 & 1.00 & 1.00 & 0.84 & 1.00 & 1.00 & 1.00 & 1.00 & 0.89 & 1.00 & 1.00 & 0.27 & 0.30 & 1.00 & 1.00 \\
$\mathrm{~A} 2$ & 1.00 & 1.00 & 1.00 & 1.00 & 1.00 & 1.00 & 1.00 & 1.00 & 1.00 & 1.00 & 1.00 & 1.00 & 0.40 & 0.40 & 0.87 & 0.80 \\
$\mathrm{~A} 3$ & 0.63 & 0.61 & 0.79 & 0.87 & 0.78 & 0.84 & 0.91 & 0.84 & 0.77 & 1.00 & 0.69 & 0.87 & 0.56 & 0.50 & 0.80 & 0.56 \\
$\mathrm{~A} 4$ & 1.00 & 1.00 & 1.00 & 0.83 & 1.00 & 1.00 & 1.00 & 1.00 & 1.00 & 1.00 & 0.69 & 0.63 & 0.42 & 0.65 & 0.57 & 0.57 \\
$\mathrm{~A} 5$ & 0.58 & 0.53 & 0.67 & 0.66 & 0.73 & 0.72 & 0.69 & 0.83 & 0.53 & 0.83 & 0.58 & 0.44 & 1.00 & 1.00 & 0.61 & 0.43 \\
$\mathrm{~A} 6$ & 0.63 & 0.69 & 0.72 & 0.72 & 0.73 & 0.77 & 0.69 & 0.77 & 0.67 & 1.00 & 0.53 & 0.55 & 0.89 & 1.00 & 0.65 & 0.39 \\
\hline
\end{tabular}

Table 11 Aggravated decision-making matrix

\begin{tabular}{llllllllllllllllll}
\hline & $\mathrm{C}_{11}$ & $\mathrm{C}_{12}$ & $\mathrm{C}_{13}$ & $\mathrm{C}_{14}$ & $\mathrm{C}_{21}$ & $\mathrm{C}_{22}$ & $\mathrm{C}_{23}$ & $\mathrm{C}_{24}$ & $\mathrm{C}_{31}$ & $\mathrm{C}_{32}$ & $\mathrm{C}_{33}$ & $\mathrm{C}_{34}$ & $\mathrm{C}_{41}$ & $\mathrm{C}_{42}$ & $\mathrm{C}_{43}$ & $\mathrm{C}_{44}$ \\
\hline $\mathrm{A} 1$ & 0.07 & 0.05 & 0.05 & 0.06 & 0.07 & 0.06 & 0.06 & 0.06 & 0.05 & 0.06 & 0.05 & 0.05 & 0.02 & 0.02 & 0.07 & 0.06 \\
$\mathrm{~A} 2$ & 0.07 & 0.05 & 0.05 & 0.06 & 0.09 & 0.06 & 0.06 & 0.06 & 0.05 & 0.07 & 0.05 & 0.05 & 0.04 & 0.02 & 0.06 & 0.05 \\
$\mathrm{~A} 3$ & 0.04 & 0.03 & 0.04 & 0.05 & 0.07 & 0.05 & 0.05 & 0.05 & 0.04 & 0.07 & 0.03 & 0.04 & 0.05 & 0.03 & 0.05 & 0.04 \\
$\mathrm{~A} 4$ & 0.07 & 0.05 & 0.05 & 0.05 & 0.09 & 0.06 & 0.06 & 0.06 & 0.05 & 0.07 & 0.03 & 0.03 & 0.04 & 0.04 & 0.04 & 0.04 \\
$\mathrm{~A} 5$ & 0.04 & 0.03 & 0.03 & 0.04 & 0.06 & 0.05 & 0.04 & 0.05 & 0.03 & 0.06 & 0.03 & 0.02 & 0.09 & 0.06 & 0.04 & 0.03 \\
$\mathrm{~A} 6$ & 0.04 & 0.04 & 0.04 & 0.04 & 0.06 & 0.05 & 0.04 & 0.05 & 0.03 & 0.07 & 0.02 & 0.03 & 0.08 & 0.06 & 0.04 & 0.03 \\
Max & 0.07 & 0.05 & 0.05 & 0.06 & 0.09 & 0.06 & 0.06 & 0.06 & 0.05 & 0.07 & 0.05 & 0.05 & 0.09 & 0.06 & 0.07 & 0.06 \\
Min & 0.04 & 0.03 & 0.03 & 0.04 & 0.06 & 0.05 & 0.04 & 0.05 & 0.03 & 0.06 & 0.02 & 0.02 & 0.02 & 0.02 & 0.04 & 0.03 \\
\hline
\end{tabular}


Table 12 Results of CRADIS method

\begin{tabular}{lllllll}
\hline & $s_{i}^{+}$ & $K_{i}^{+}$ & $s_{i}^{-}$ & $K_{i}^{-}$ & $Q_{i}$ & Rank \\
\hline A1 & 0.5825 & 0.7742 & 0.5689 & 0.8122 & 0.7932 & 2 \\
A2 & 0.5643 & 0.7992 & 0.5871 & 0.8382 & 0.8187 & 1 \\
A3 & 0.7042 & 0.6403 & 0.4471 & 0.6384 & 0.6393 & 4 \\
A4 & 0.6238 & 0.7229 & 0.5276 & 0.7532 & 0.7380 & 3 \\
A5 & 0.7558 & 0.5966 & 0.3956 & 0.5647 & 0.5807 & 6 \\
A6 & 0.7277 & 0.6197 & 0.4237 & 0.6049 & 0.6123 & 5 \\
OA & 0.4509 & & 0.7005 & & & \\
\hline
\end{tabular}

Table 13 Rank of alternatives

\begin{tabular}{llllllll}
\hline & MARCOS & MABAC & SAW & ARAS & WASPAS & TOPSIS & CRADIS \\
\hline A1 & 2 & 2 & 2 & 2 & 2 & 2 & 2 \\
A2 & 1 & 1 & 1 & 1 & 1 & 1 & 1 \\
A3 & 4 & 4 & 4 & 5 & 4 & 6 & 4 \\
A4 & 3 & 3 & 3 & 3 & 3 & 3 & 3 \\
A5 & 6 & 6 & 6 & 6 & 6 & 5 & 6 \\
A6 & 5 & 5 & 5 & 4 & 5 & 4 & 5 \\
\hline
\end{tabular}

Table 14 Spearman correlation coefficient results

\begin{tabular}{llllllll}
\hline & MARCOS & MABAC & SAW & ARAS & WASPAS & TOPSIS & CRADIS \\
\hline MARCOS & 1.000 & 1.000 & 1.000 & 0.943 & 1.000 & 0.829 & 1.000 \\
MABAC & 1.000 & 1.000 & 1.000 & 0.943 & 1.000 & 0.829 & 1.000 \\
SAW & 1.000 & 1.000 & 1.000 & 0.943 & 1.000 & 0.829 & 1.000 \\
ARAS & 0.943 & 0.943 & 0.943 & 1.000 & 0.943 & 0.943 & 0.943 \\
WASPAS & 1.000 & 1.000 & 1.000 & 0.943 & 1.000 & 0.829 & 1.000 \\
TOPSIS & 0.829 & 0.829 & 0.829 & 0.943 & 0.829 & 1.000 & 0.829 \\
CRADIS & 1.000 & 1.000 & 1.000 & 0.943 & 1.000 & 0.829 & 1.000 \\
\hline
\end{tabular}

ranking of alternatives is unchanged and thus, the results obtained by the CRADIS method are confirmed.

\section{Discussion}

In this study, extended sustainability criteria were applied to evaluate different types of incinerators. Four main criteria were used: ecological, economic, social, and technical criteria. By applying these criteria, the sustainability in the application of incinerators and their technical characteristics were considered. Each of these criteria was further broken down into four sub-criteria. This was done in order not to give greater importance to a 


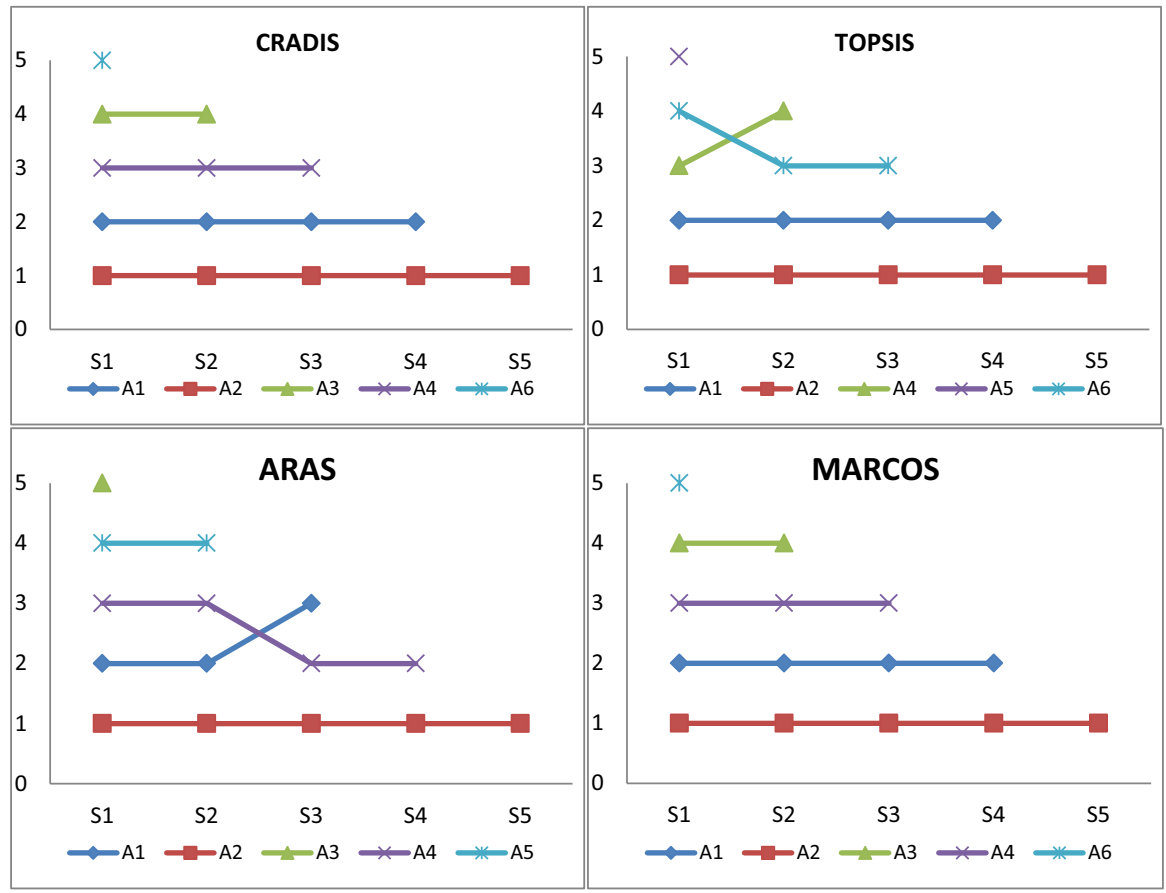

Fig. 1 Dynamic decision matrix effects

certain main criterion compared to other criteria. The assessment of the sustainability criteria was done using expert decision-making, while the technical criteria were completed based on the technical characteristics of the device. Since there are several criteria according to which the evaluation of incinerators was performed, the logical choice for solving this problem is the application of the MCDA method.

Before alternatives were ranked, it was necessary to first determine the importance of individual criteria. Determining the importance of criteria or weights was done using the FUCOM method. The FUCOM method is a relatively new MCDA method used to determine weight criteria (Pamučar et al., 2018). The advantage of the FUCOM method over the AHP method is that the decision maker has fewer comparisons. In relation to the BWM (Best-Worst Method) and PIPRECIA (Pivot Pairwise Relative Criteria Importance Assessment) method, it is not necessary to determine the best and worst criteria, but only to rank the criteria according to the importance of what is done with the FUCOM method. After the weights were determined, the alternatives were ranked using the CRADIS method. Based on the obtained results, it was determined that CRADIS and MARCOS methods have consistency for determining the ranking, while the TOPSIS and ARAS methods do not. The reason for this should be sought in the following. The TOPSIS method developed by Hwang and Yoon (1981) applies the Euclidean distance to calculate from ideal and anti-ideal solutions. The TOPSIS method calculates the ideal and anti-ideal solution at the level of individual criteria for alternatives without considering all the criteria. It puts the alternatives in relation to ideal and anti-ideal solution for each criterion, and at the end the deviations of the alternatives from these solutions are added up. The problem often cited 


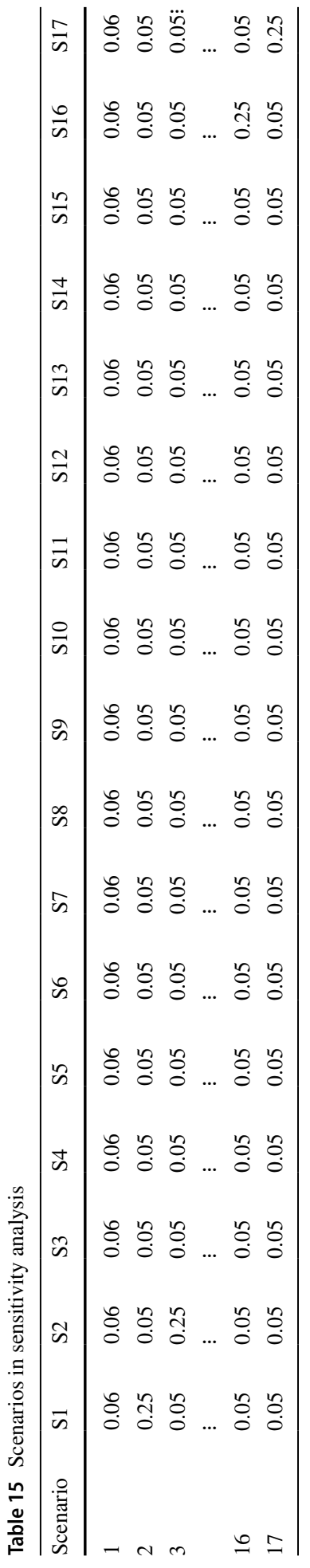




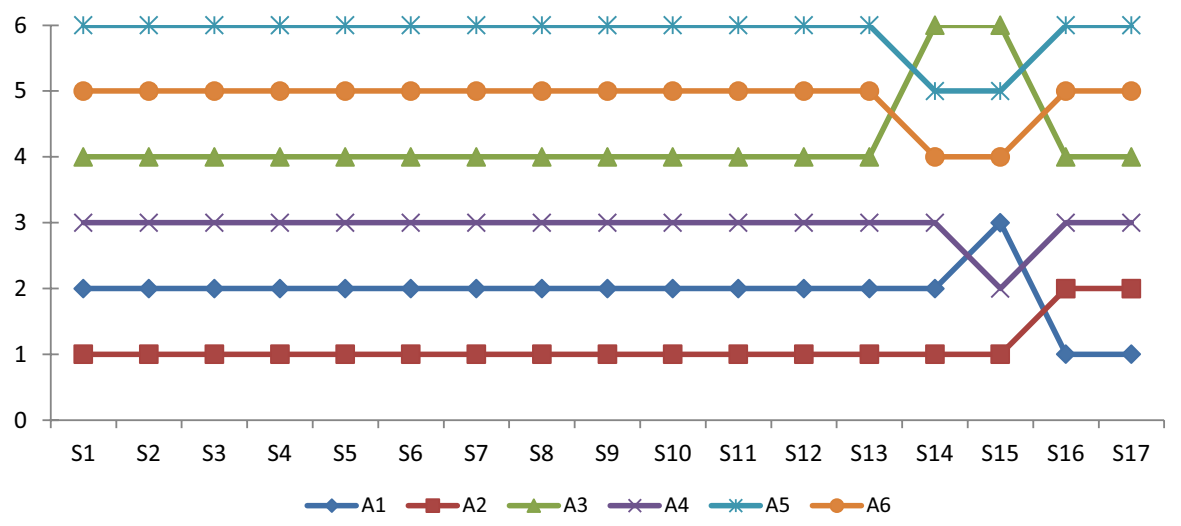

Fig. 2 Results of sensitivity analysis

with the TOPSIS method is about which are the ideal and anti-ideal solutions (Wang, et al., 2014).

The ARAS method provided a different ranking order primarily due to the type of normalization it applies. Applying the same normalization as with the CRADIS method, the same rank order was obtained. The ARAS method uses the utility function, but in relation to the ideal solution without considering the anti-ideal solution (Zavadskas \& Turskis, 2010). The MARCOS method calculates the utility function in relation to the ideal and anti-ideal solution, and in addition applies the same normalization as the CRADIS method. Therefore, the same ranking order was obtained. The CRADIS method, unlike the MARCOS method, calculates the ideal and anti-ideal solution after the decision matrix becomes aggravated, while the MARCOS in the first step forms an initial decision matrix that includes the ideal and anti-ideal solution. Also, the results obtained by the CRADIS method were confirmed by the MABAC, SAW, and WASPAS methods.

The CRADIS method is characterized with the great flexibility in its application. It is possible to apply all types of normalization and their effects will not be mitigated by applying other steps as is the case with the VIKOR method (MULTI-Criterion Optimization and Compromise Solution). The VIKOR method defines the use of certain normalization, and the effects of applying different normalizations are neutralized (Opricovic \& Tzeng, 2004). In addition, the CRADIS method allows the modification of the algorithm so that it is possible to apply other methods for calculating deviations. As with the TOPSIS method, the authors Wang, and Wang (2014) applied Mahalanobis distances instead of Euclidean distances. All this is the reason why the CRADIS method should be used when ranking alternatives.

The results of the sensitivity analysis have shown that there are certain shortcomings in conducting this study that is about comparison of different types of incinerators from one manufacturer. INCINER8 Limited uses the same technology, and the incinerators basically differ only in technical specifications. Therefore, in 13 scenarios, the same ranking was obtained. The last four criteria changed the ranking. However, the aim of this paper is to recognize which of the six types of analyzed incinerators would best suit the secondary healthcare institutions in $\mathrm{B} \& \mathrm{H}$.

The conducted sensitivity analysis has confirmed that alternative A2 (I8-M50) best meets the objectives of these institutions according to expert assessments, followed by 
alternative A1 (I8-M40). The reason for this should be sought in the fuel consumption and the impact on the environment (Ciplak, 2015). Therefore, it is necessary to make a compromise between capacity, consumption, and impact on the environment as well as on human health. Small incinerators have less impact on the environment than larger ones because they consume less fuel and destroy less waste. Community acceptance is better; they take up less space and have a lower cost compared to large incinerators. These smaller incinerators can also be installed in settlements because they do not affect air pollution in high volume. Due to consumption and the impact on the environment, large incinerators need to be slightly distanced from the settlement. Therefore, it is necessary to respect all standards when making incinerators to minimize the impact on the environment.

\section{Conclusion}

The management of $\mathrm{HCW}$ gets increasing importance due to the increasing amount of waste that occurs during the operation of healthcare institutions. There are different types of HCW that can be treated in different ways. Waste incineration is one of ways how HCW can be managed. HCW incineration has certain advantages and disadvantages, and when choosing an HCW incinerator, a systematic approach must be applied, and all relevant criteria must be included. It is necessary to include different criteria in the selection of incinerator, of which the sustainability criteria together with the technical criteria are the most important. Due to the existence of several criteria in the selection of HCW treatment, this decision problem is solved by applying MCDM.

This study applied a combination of two MCDA methods, namely FUCOM and CRADIS methods in the selection of HCW incinerators for the needs of secondary healthcare institutions in $\mathrm{B} \& \mathrm{H}$. The technical characteristics of the incinerators and the expert assessments of the sustainability criteria were used. A total of four main criteria were applied, which are further broken down into four sub-criteria. The weights of criteria and sub-criteria were determined by the FUCOM method. The CRADIS method was used to rank HCW incinerators manufactured by INCINER8 Limited. Of the six incinerators taken as alternatives, the best ranked incinerator is A2 (I8-M50) which also showed the best results when applying different MCDA methods and applying sensitivity analysis. Based on the obtained research results, it can be concluded that it is the first choice for incinerators from this manufacturer for the needs of secondary healthcare institutions in $\mathrm{B} \& \mathrm{H}$.

The shortcoming of this study can be found from the fact that the selection of incinerators was taken from only one producer. The reason is that the company Derby trade, that provided experts for evaluation, is the distributor of incinerators of this manufacturer, and no other manufacturers were taken into consideration. This limitation is also present in the technical characteristics of incinerators because the same $\mathrm{HCW}$ incineration technology is applied in all incinerators, and therefore, there are no large differences in the ratings of incinerators. However, the focus of this study is on the application of the multi-criteria analysis method in the selection of incinerators and the development of the CRADIS method that applies the steps of existing methods.

The specificity of this paper is that the original CRADIS multi-criteria methodology was used for the selection of incinerators, which combines the advantages of the existing multi-criteria methods MARCOS, ARAS, and TOPSIS. The CRADIS method has shown simplicity and flexibility, which represent significant recommendations for solving other real and practical problems. The method was tested and compared with other MCDA 
methods. When using the other six MCDA methods, the same ranking was obtained for the four methods as for the CRADIS method. Further analysis in a dynamic environment of the CRADIS method has shown resistance to rank reversal problems. This consistency has been also shown by the MARCOS method, while the ARAS and TOPSIS methods have shown inconsistency in the ranking of alternatives. This analysis has confirmed the robustness of the solution and the stability of the CRADIS method, which recommends it for further application in decision support systems.

The algorithm of the CRADIS method can be modified using different types of normalization, as well as by application of different methods for calculating the distance between ideal and anti-ideal points, which represents some of the directions of future research. A practical example has shown how the CRADIS method can be used in combination with other MCDA methods. Therefore, other methods for determining the weights of the criteria may be applied in future research. In addition, it is possible to develop more advanced forms of the CRADIS method such as the fuzzy and rough approach in solving MCDM methods.

\section{References}

Adar, T., \& Delice, E. K. (2019). New integrated approaches based on MC-HFLTS for healthcare waste treatment technology selection. Journal of Enterprise Information Management, 32(4), 688-711. https://doi.org/10.1108/jeim-10-2018-0235

Asadabadi, M. R., Chang, E., \& Saberi, M. (2019). Are MCDM methods useful? A critical review of analytic hierarchy process (AHP) and analytic network process (ANP). Cogent Engineering, 6(1), 1623153. https://doi.org/10.1080/23311916.2019.1623153

Aung, T. S., Luan, S., \& Xu, Q. (2019). Application of multi-criteria-decision approach for the analysis of medical waste management systems in Myanmar. Journal of Cleaner Production. https://doi.org/10. 1016/j.jclepro.2019.03.049

Azizkhani, N. A., Gholami, S., Yusif, S., Moosavi, S., Miri, S. F., \& Kalhor, R. (2021). Comparison of health-care waste management in urban and rural areas in Iran: Application of multi-criteria decision making method. Health Scope, 10(2), e113282. https://doi.org/10.5812/jhealthscope.113282

Badi, I., \& Kridish, M. (2020). Landfill site selection using a novel FUCOM-CODAS model: A case study in Libya. Scientific African, 9, e00537. https://doi.org/10.1016/j.sciaf.2020.e00537

Badi, I., Shetwan, A., \& Hemeda, A. (2019). A grey-based assessment model to evaluate health-care waste treatment alternatives in Libya. Operational Research in Engineering Sciences: Theory and Applications, 2(3), 92-106. https://doi.org/10.31181/oresta1903092b

Belhadi, A., Kamble, S. S., Khan, S. A. R., Touriki, F. E., \& Kumar, M. D. (2020). Infectious waste management strategy during covid-19 pandemic in Africa: An integrated decision-making framework for selecting sustainable technologies. Environmental Management, 66, 1085-1104. https://doi.org/10. 1007/s00267-020-01375-5

Biswas, T. K., Chaki, S., \& Das, M. C. (2019). MCDM technique application to the selection of an Indian institute of technology. Operational Research in Engineering Sciences: Theory and Applications, 2(3), 65-76. https://doi.org/10.31181/oresta1903065b

Bozanić, D., Tešić, D., \& Kočić, J. (2019). Multi-criteria FUCOM-Fuzzy MABAC model for the selection of location for construction of single-span bailey bridge. Decision Making: Applications in Management and Engineering, 2(1), 132-146. https://doi.org/10.31181/dmame1901132b

Cao, Q., Esangbedo, M. O., Bai, S., \& Esangbed, C. O. (2019). Grey SWARA-FUCOM weighting method for contractor selection MCDM problem: A case study of floating solar panel energy system installation. Energies, 12(13), 2481. https://doi.org/10.3390/en12132481

Carnero, M. C. (2020). Waste segregation FMEA model integrating intuitionistic fuzzy set and the PAPRIKA method. Mathematics, 8(8), 1375. https://doi.org/10.3390/math8081375

Chauhan, A., \& Singh, A. (2016). A hybrid multi-criteria decision making method approach for selecting a sustainable location of healthcare waste disposal facility. Journal of Cleaner Production, 139, 1001-1010. https://doi.org/10.1016/j.jclepro.2016.08.098 
Chen, X., Lin, J., Li, X., \& Ma, Z. (2021). A novel framework for selecting sustainable healthcare waste treatment technologies under Z-number environment. Journal of the Operational Research Society, 72(9), 2032-2045. https://doi.org/10.1080/01605682.2020.1759382

Ciplak, N. (2015). Assessing future scenarios for health care waste management using a multi-criteria decision analysis tool: A case study in the Turkish West Black Sea Region. Journal of the Air \& Waste Management Association, 65(8), 919-929. https://doi.org/10.1080/10962247.2015.1038398

Ciplak, N. (2013). A system dynamics approach for the determination of adverse health impacts of healthcare waste incinerators and landfill sites on employees. Environmental Management and Sustainable Development, 2(2), 7-28. https://doi.org/10.5296/emsd.v2i2.3688

Đalić, I., Stević, Ž, Karamasa, C., \& Puška, A. (2020). A novel integrated fuzzy PIPRECIA-interval rough SAW model: Green supplier selection. Decision Making: Applications in Management and Engineering, 3(1), 126-145. https://doi.org/10.31181/dmame2003114d

Datta, P., Mohi, G. K., \& Chander, J. (2018). Biomedical waste management in India: Critical appraisal. Journal of Laboratory Physicians, 10, 6-14. https://doi.org/10.4103/JLP.JLP_89_17

Durmić, E. (2019). Evaluation of criteria for sustainable supplier selection using FUCOM method. Operational Research in Engineering Sciences: Theory and Applications, 2(1), 91-107. https://doi.org/10. 31181/oresta1901085d

Durmić, E., Stević, Ž, Chatterjee, P., Vasiljević, M., \& Tomašević, M. (2020). Sustainable supplier selection using combined FUCOM-rough SAW model. Reports in Mechanical Engineering, 1(1), 34-43. https://doi.org/10.31181/rme200101034c

Dursun, M., Karsak, E. E., \& Karadayi, M. A. (2011). Assessment of health-care waste treatment alternatives using fuzzy multi-criteria decision making approaches. Resources, Conservation and Recycling, 57, 98-107. https://doi.org/10.1016/j.resconrec.2011.09.012

Fazlollahtabar, H., Smailbašić, A., \& Stević, Ž. (2019). FUCOM method in group decision-making: Selection of forklift in a warehouse. Decision Making: Applications in Management and Engineering, 2(1), 49-65. https://doi.org/10.31181/dmame1901065f

Fetanat, A., Tayebi, M., \& Shafipour, G. (2021). Management of waste electrical and electronic equipment based on circular economy strategies: Navigating a sustainability transition toward waste management sector. Clean Technologies and Environmental Policy, 23(2), 343-369. https://doi.org/10.1007/ s10098-020-02006-7

Geetha, S., Narayanamoorthy, S., Kang, D., \& Kureethara, J. V. (2019). A novel assessment of healthcare waste disposal methods: intuitionistic hesitant fuzzy MULTIMOORA decision making approach. IEEE Access, 7, 130283-130299. https://doi.org/10.1109/access.2019.2940540

Hinduja, A., \& Pandey, M. (2019). Assessment of healthcare waste treatment alternatives using an integrated decision support framework. International Journal of Computational Intelligence Systems, 12(1), 318-333. https://doi.org/10.2991/ijcis.2019.0022

Hoan, P., \& Ha, Y. (2021). ARAS-FUCOM approach for VPAF fighter aircraft selection. Decision Science Letters, 10(1), 53-62. https://doi.org/10.5267/j.ds1.2020.10.004

Hossain, M. S., Balakrishnan, V., Rahman, N. N. N. A., Sarker, M. Z. I., \& Kadir, M. O. A. (2012). Treatment of clinical solid waste using a steam autoclave as a possible alternative technology to incineration. International Journal of Environmental Research and Public Health, 9(3), 855-867. https://doi. org/10.3390/ijerph9030855

Hu, H., Li, X., Nguyen, A. D., \& Kavan, P. A. (2015). Critical evaluation of waste incineration plants in Wuhan (China) based on site selection, environmental influence, public health and public participation. International Journal of Environmental Research and Public Health, 12, 7593-7614. https://doi. org/10.3390/ijerph120707593

Hwang, C. L., \& Yoon, K. (1981). Multiple attribute decision making. In Lecture Notes in Economics and Mathematical Systems (Vol. 186). Springer, Berlin

Karagoz, S., Deveci, M., Simic, V., Aydin, N., \& Bolukbas, U. (2020). A novel intuitionistic fuzzy MCDM-based CODAS approach for locating an authorized dismantling center: A case study of Istanbul. Waste Management \& Research, 38(6), 660-672. https://doi.org/10.1177/0734242x19 899729

Khoshand, A., Khanlari, K., Abbasianjahromi, H., \& Zoghi, M. (2020). Construction and demolition waste management: Fuzzy analytic hierarchy process approach. Waste Management \& Research: THe Journal for a Sustainable Circular Economy, 38(7), 773-782. https://doi.org/10.1177/07342 $42 \times 20910468$

Kumar, R., Somrongthong, R., \& Shaikh, B. T. (2015). Effectiveness of intensive healthcare waste management training model among health professionals at teaching hospitals of Pakistan: A quasi-experimental study. BMC Health Services Research, 15(1), 81. https://doi.org/10.1186/ s12913-015-0758-7 
Lee, S., Vaccari, M., \& Tudor, T. (2016). Considerations for choosing appropriate healthcare waste management treatment technologies: A case study from an East Midlands NHS Trust, in England. Journal of Cleaner Production, 135, 139-147. https://doi.org/10.1016/j.jclepro.2016.05.166

Li, H., Li, J., Zhang, Z., Cao, X., Zhu, J., \& Chen, W. (2020). Establishing an interval-valued fuzzy decision-making method for sustainable selection of healthcare waste treatment technologies in the emerging economies. Journal of Material Cycles and Waste Management., 22, 501-514. https:// doi.org/10.1007/s10163-019-00943-0

Li, Z., Jia, X., Jin, H., Ma, L., Xu, C., \& Wei, H. (2021). Determining optimal municipal solid waste management scenario based on best-worst method. Journal of Environmental Engineering and Landscape Management, 29(2), 150-161. https://doi.org/10.3846/jeelm.2021.14843

Liu, H.-C., Wu, J., \& Li, P. (2013). Assessment of health-care waste disposal methods using a VIKORbased fuzzy multi-criteria decision making method. Waste Management, 33(12), 2744-2751. https://doi.org/10.1016/j.wasman.2013.08.006

Liu, H.-C., You, J.-X., Lu, C., \& Chen, Y.-Z. (2015). Evaluating health-care waste treatment technologies using a hybrid multi-criteria decision making model. Renewable and Sustainable Energy Reviews, 41, 932-942. https://doi.org/10.1016/j.rser.2014.08.061

Liu, H.-C., You, J.-X., Lu, C., \& Shan, M.-M. (2014). Application of interval 2-tuple linguistic MULTIMOORA method for health-care waste treatment technology evaluation and selection. Waste Management, 34(11), 2355-2364. https://doi.org/10.1016/j.wasman.2014.07.016

Liu, P., Rani, P., \& Mishra, A. R. (2021). A novel Pythagorean fuzzy combined compromise solution framework for the assessment of medical waste treatment technology. Journal of Cleaner Production, 292, 126047. https://doi.org/10.1016/j.jclepro.2021.126047

Lu, C., You, J.-X., Liu, H.-C., \& Li, P. (2016). Health-care waste treatment technology selection using the interval 2-tuple induced TOPSIS method. International Journal of Environmental Research and Public Health, 13(6), 562. https://doi.org/10.3390/ijerph13060562

Makan, A., \& Fadili, A. (2021). Sustainability assessment of healthcare waste treatment systems using surrogate weights and PROMETHEE method. Waste Management \& Research, 39(1), 73-82. https://doi.org/10.1177/0734242x20947162

Matić, B., Jovanović, S., Das, D. K., Zavadskas, E. K., Stević, Ž, Sremac, S., \& Marinković, M. (2019). A new hybrid MCDM model: Sustainable supplier selection in a construction company. Symmetry, 11(3), 353. https://doi.org/10.3390/sym11030353

Mishra, A. R., Mardani, A., Rani, P., \& Zavadskas, E. K. (2020). A novel EDAS approach on intuitionistic fuzzy set for assessment of health-care waste disposal technology using new parametric divergence measures. Journal of Cleaner Production, 272, 122807. https://doi.org/10.1016/j.jclep ro.2020.122807

Narayanamoorthy, S., Annapoorani, V., Kang, D., Baleanu, D., Jeon, J., Kureethara, J. V., \& Ramya, L. (2020). A novel assessment of bio-medical waste disposal methods using integrating weighting approach and hesitant fuzzy MOOSRA. Journal of Cleaner Production, https://doi.org/10.1016/j. jclepro.2020.122587

Nunić, Z. (2018). Evaluation and selection of manufacturer PVC carpentry using FUCOM-MABAC model. Operational Research in Engineering Sciences: Theory and Applications, 1(1), 13-28. https://doi.org/10.31181/oresta19012010113n

OpricovicTzeng, S.G.-H. (2004). Compromise solution by MCDM methods: A comparative analysis of VIKOR and TOPSIS. European Journal of Operational Research, 156(2), 445-455. https://doi.org/ 10.1016/S0377-2217(03)00020-1

Pamučar, D., \& Ćirović, G. (2015). The selection of transport and handling resources in logistics centers using multi-attributive border approximation area comparison (MABAC). Expert Systems with Applications, 42(6), 3016-3028. https://doi.org/10.1016/j.eswa.2014.11.05

Pamučar, D., Puška, A., Stević, Ž, \& Ćirović, G. (2021). A new intelligent MCDM model for HCW management: The integrated BWM-MABAC model based on D numbers. Expert Systems with Applications, 175, 114862. https://doi.org/10.1016/j.eswa.2021.114862

Pamučar, D., Stević, Ž, \& Sremac, S. (2018). A new model for determining weight coefficients of criteria in MCDM models: Full consistency method (FUCOM). Symmetry, 10(9), 393. https://doi.org/ 10.3390/sym 10090393

Rafiee, A., Yaghmaeian, K., Hoseini, M., Parmy, S., Mahvi, A., Yunesian, M., Khaefi, M., \& Nabizadeh, R. (2016). Assessment and selection of the best treatment alternative for infectious waste by modified Sustainability Assessment of Technologies methodology. Journal of Environmental Health Science and Engineering, 14(1), 10. https://doi.org/10.1186/s40201-016-0251-1

Ramaci, T., Barattucci, M., Ledda, C., \& Rapisarda, V. (2020). Social stigma during COVID-19 and its impact on HCWs outcomes. Sustainability, 12(9), 3834. https://doi.org/10.3390/su12093834 
Rozman, Č, Grgić, Z., Maksimović, A., Ćejvanović, F., Puška, A., \& Šakić Bobić, B. (2016). Multiple-criteria approach of evaluation of milk farm models in Bosnia and Herzegovina. Mljekarstvo, 66(3), 206-214. https://doi.org/10.15567/mljekarstvo.2016.0305

Rozman, Č, Maksimović, A., Puška, A., Grgić, Z., Pažek, K., Prevolšek, B., \& Ćejvanović, F. (2017). The use of multi criteria models for decision support system in fruit production. Erwerbs-Obstbau, 59(3), 235-243. https://doi.org/10.1007/s10341-017-0320-3

Shi, H., Liu, H.-C., Li, P., \& Xu, X.-G. (2017). An integrated decision making approach for assessing healthcare waste treatment technologies from a multiple stakeholder. Waste Management, 59, 508-517. https://doi.org/10.1016/j.wasman.2016.11.016

Stević, Ž, \& Brković, N. (2020). A novel integrated FUCOM-MARCOS model for evaluation of human resources in a transport company. Logistics, 4(1), 4. https://doi.org/10.3390/logistics4010004

Stević, Ž, Durmić, E., Gajić, M., Pamučar, D., \& Puška, A. (2019). A Novel multi-criteria decisionmaking model: Interval rough SAW method for sustainable supplier selection. Information, 10(10), 292. https://doi.org/10.3390/info10100292

Stević, Ž, Pamučar, D., Puška, A., \& Chatterjee, P. (2020). Sustainable supplier selection in healthcare industries using a new MCDM method: Measurement alternatives and ranking according to compromise solution (MARCOS). Computers \& Industrial Engineering, 140, 106231. https://doi.org/ 10.1016/j.cie.2019.106231

Taghipour, H., Mohammadyarei, T., Asghari Jafarabadi, M., \& Asl Hashemi, A. (2014). On-site or offsite treatment of medical waste: A challenge. Journal of Environmental Health Science and Engineering, 12(1), 68. https://doi.org/10.1186/2052-336x-12-68

Thakur, V., \& Ramesh, A. (2015). Healthcare waste management research: A structured analysis and review (2005-2014). Waste Management \& Research, 33(10), 855-870. https://doi.org/10.1177/ $0734242 \times 15594248$

Torkayesh, A. E., Malmir, B., \& Rajabi Asadabadi, M. (2021). Sustainable waste disposal technology selection: The stratified best-worst multi-criteria decision-making method. Waste Management, 122, 100-112. https://doi.org/10.1016/j.wasman.2020.12.040

Voudrias, E. A. (2016). Technology selection for infectious medical waste treatment using the analytic hierarchy process. Journal of the Air \& Waste Management Association, 66(7), 663-672. https:// doi.org/10.1080/10962247.2016.1162226

Wang, P., Zhu, Z., \& Huang, S. (2014). The use of improved TOPSIS method based on experimental design and Chebyshev regression in solving MCDM problems. Journal of Intelligent Manufacturing, 28(1), 229-243. https://doi.org/10.1007/s10845-014-0973-9

Wang, Z.-X., \& Wang, Y.-Y. (2014). Evaluation of the provincial competitiveness of the Chinese hightech industry using an improved TOPSIS method. Expert Systems with Applications, 41(6), 28242831. https://doi.org/10.1016/j.eswa.2013.10.015

Wei, C., \& Liao, H. (2016). A Multigranularity linguistic group decision-making method based on hesitant 2-tuple sets. International Journal of Intelligent Systems, 31(6), 612-634. https://doi.org/10. 1002 /int. 21798

Xiao, F. (2018). A novel multi-criteria decision making method for assessing health-care waste treatment technologies based on D numbers. Engineering Applications of Artificial Intelligence, 71, 216-225. https://doi.org/10.1016/j.engappai.2018.03.002

Xu, Y., Yeh, C.-H., Yang, S., \& Gupta, B. (2020). Risk-based performance evaluation of improvement strategies for sustainable e-waste management. Resources, Conservation and Recycling, 155, 104664. https://doi.org/10.1016/j.resconrec.2019.104664

Yazdani, M., Chatterjee, P., Pamucar, D., \& Chakraborty, S. (2020). Development of an integrated decision making model for location selection of logistics centers in the Spanish autonomous communities. Expert Systems with Applications. https://doi.org/10.1016/j.eswa.2020.113208

Zavadskas, E. K., \& Turskis, Z. (2010). A new additive ratio assessment (ARAS) method in multicriteria decision making. Technological and Economic Development of Economy, 16(2), 159-172. https:// doi.org/10.3846/tede.2010.10

Zhang, C., Hu, Q., Zeng, S., \& Su, W. (2021). IOWLAD-based MCDM model for the site assessment of a household waste processing plant under a Pythagorean fuzzy environment. Environmental Impact Assessment Review, 89, 106579. https://doi.org/10.1016/j.eiar.2021.106579

Publisher's Note Springer Nature remains neutral with regard to jurisdictional claims in published maps and institutional affiliations. 


\section{Authors and Affiliations}

\section{Adis Puška ${ }^{1}$ (D) . Željko Stević ${ }^{2} \cdot$ Dragan Pamučar $^{3}$}

Željko Stević

zeljkostevic88@yahoo.com

Dragan Pamučar

dragan.pamucar@va.mod.gov.rs

1 University of Bijeljina, Pavlovića put bb, 76300 Bijeljina, Bosnia and Herzegovina

2 Faculty of Transport and Traffic Engineering, University of East Sarajevo, Vojvode Mišića 52, 74000 Doboj, Bosnia and Herzegovina

3 Department of Logistics, Military Academy, University of Defence in Belgrade, Pavla Jurišića Šturma 33, 11000 Belgrade, Serbia 